\title{
THE ABSORPTION OF RADIOIRON LABELED FOODS AND IRON SALTS IN NORMAL AND IRON-DEFICIENT SUBJECTS AND IN IDIOPATHIC HEMOCHROMATOSIS
}

\author{
BY ROBERT B. CHODOS, 1 JOSEPH F. ROSS, 2 LEONARD APT, ${ }^{2}$ MYRON \\ POLLYCOVE, AND JAMES A. E. HALKETT
}

\author{
(From the Radioisotope Unit and Medical Service, Veterans Administration Hospital, Boston, \\ the Department of Medicine, Boston University School of Medicine, the Department \\ of Pediatrics, Harvard Medical School, and the Department of Medicine, Tufts \\ University School of Medicine, Boston, Mass.)
}

(Submitted for publication September 7, 1956; accepted November 7, 1956)

It is generally accepted that, in the absence of bleeding or pregnancy, approximately $1 \mathrm{mg}$. of iron is lost per day from the body (1-11). As a corollary, the quantity of iron in the body is largely determined by the amount of iron absorbed from the gastrointestinal tract. Fundamental knowledge of iron absorption has been obtained by balance studies $(2,4,12-18)$, by determination of the increase in the serum iron level (19) or circulating hemoglobin (20-21) after oral iron administration, and by evaluation of the percentage of orally administered radioiron incorporated into hemoglobin (22-26) or accounted for in both hemoglobin and feces $(7,27)$.

The present investigation was undertaken to compare the absorption of egg and vegetable iron with that of iron salts fed to normal subjects, to patients with iron-deficiency, and to patients with idiopathic hemochromatosis. The method of study used was similar to that introduced by Dubach, Callender, and Moore (27). These investigators showed that the quantity of iron used in hemoglobin formation may not always be a true index of iron absorption $(27,28)$. Since a negligible quantity of iron is excreted into the intestinal tract $(1-3,7-8,11)$ and since stool iron is almost entirely unabsorbed dietary iron (2), additional information concerning iron absorption may be obtained by determining both the percentage of orally administered radioiron incorporated into hemo-

1 Present address: VA Hospital, Syracuse, New York.

2 Present address: School of Medicine, University of California, Los Angeles, California.

- Present address: Wills Eye Hospital, Philadelphia, Pennsylvania.

4 Present address: Donner Laboratory, University of California, Berkeley, California. globin and the percentage recovered in the feces. The percentage of the oral dose not recovered in hemoglobin and feces may be considered an approximate measure of the quantity of iron deposited in tissue stores. In certain patients this figure may be subject to a significant experimental error due particularly to incomplete stool collection.

\section{EXPERIMENTAL SUBJECTS AND METHODS}

Three groups of patients were studied:

1. Normal subjects. This group consisted of 32 male patients with uncomplicated dermatitis, psychosomatic or psychiatric illnesses, or neurologic diseases. All had normal hematologic and serum iron values. Iron stores were not specifically measured by tissue biopsy (bone marrow or liver). Blood loss was excluded by history and stool examination. Systemic diseases that might influence iron absorption, utilization, or the level of iron stores were excluded by appropriate laboratory and clinical evaluation.

2. Subjects with deficient iron stores. This group comprised 15 patients with evidence of chronic blood loss. The red blood cells were hypochromic and microcytic, serum iron levels were less than 50 micrograms per 100 $\mathrm{ml}$. and a definite history of blood loss was obtained in each case.

3. Subjects with excess iron stores. This group of 9 patients had idiopathic hemochromatosis. The diagnosis was established by clinical features, elevated serum iron level, and by liver or skin biopsy.

The number of absorption studies and the form in which the iron was administered to these subjects are summarized in Table I.

Red blood cell indices were determined for each subject using equipment certified by the Bureau of Standards. Serum iron was measured by the method of Kitzes, Elvehjem, and Schuette (29). The whole blood, red cell, and plasma volumes were estimated using a radiophosphorus tagged red cell method (30).

Following these studies, tracer doses of radioiron were given by mouth to the fasting subject either as ferrous or 
TABLE I

Summary of iron absorption studies

\begin{tabular}{|c|c|c|c|c|c|c|}
\hline \multirow[b]{3}{*}{ Group } & \multirow[b]{3}{*}{ No. } & \multicolumn{4}{|c|}{ Iron-59 administered } & \multirow{3}{*}{$\begin{array}{l}\text { Total } \\
\text { no. of } \\
\text { studies }\end{array}$} \\
\hline & & \multirow{2}{*}{\multicolumn{2}{|c|}{$\underset{\mathrm{FeCl}}{\mathrm{As}} \underset{\mathbf{F e C l}}{\mathrm{As}}$}} & \multicolumn{2}{|c|}{ As labeled food } & \\
\hline & & & & Eggs & $\begin{array}{l}\text { Vege- } \\
\text { tables }\end{array}$ & \\
\hline $\begin{array}{l}\text { Normal } \\
\text { Iron deficient } \\
\text { Hemochromatosis }\end{array}$ & $\begin{array}{r}32 \\
15 \\
9\end{array}$ & $\begin{array}{l}25 \\
14 \\
13\end{array}$ & $\begin{array}{l}2 \\
2 \\
0\end{array}$ & $\begin{array}{r}14 \\
3 \\
1\end{array}$ & $\begin{array}{l}6 \\
2 \\
2\end{array}$ & $\begin{array}{l}47 \\
21 \\
16\end{array}$ \\
\hline Total & 56 & 52 & 4 & 18 & 10 & 84 \\
\hline
\end{tabular}

ferric chloride or as a radioiron labeled food. Ferrous chloride was prepared by the reduction of ferric chloride with powdered ascorbic acid or, in 2 studies, with cysteine. The oral dose of $\mathrm{Fe}^{\mathrm{ED}} \mathrm{s}$ used in the iron salt absorption studies ranged from 12 to 50 microcuries, and from 7 to 23 microcuries in the food iron absorption studies.

In all but 7 studies evaluating the absorption of ferrous chloride, ascorbic acid tablets (total of 0.5 to $1.0 \mathrm{gm}$.) were administered concomitantly with the radioactive iron salt. A variable quantity of non-radioactive carrier iron ranging from 4 or $5 \mathrm{mg}$. to $80 \mathrm{mg}$. was usually added to the tracer dose. The smaller carrier doses were used if the absorption of food iron had been previously studied in the subject, since this dose range approximated the quantity of iron administered in the labeled foods. Larger carrier doses were used in the remaining iron salt absorption studies.

The $\mathrm{Fe}^{\mathrm{s0}}$ labeled foods were chicken eggs and vegetables. The techniques developed for preparation of these labeled foods will be reported separately (31). The quantity of iron in a given oral dose of labeled food was determined by the method of Kitzes, Elvehjem, and Schuette (29) on an aliquot of the food substance after Kjeldahl digestion with concentrated nitric, sulfuric, and perchloric acid. Representative iron content of the various foods used is tabulated in Table II.

Radioiron labeled foods were administered after a night's fast. Two pieces of bread (containing approximately $1 \mathrm{mg}$. of iron) without butter, and black coffee (no iron) with sugar were eaten with the labeled food. Eggs were served scrambled and vegetables were boiled

TABLE II

Iron content of labeled food products

\begin{tabular}{|c|c|c|c|c|c|}
\hline \multirow[b]{2}{*}{ Food product } & \multirow{2}{*}{$\begin{array}{l}\text { No. of } \\
\text { assays }\end{array}$} & \multicolumn{2}{|c|}{$\begin{array}{l}\text { Iron content } \\
\text { (mg./100 gm.) }\end{array}$} & \multicolumn{2}{|c|}{ Iron administered } \\
\hline & & Range & Average & Range & Average \\
\hline $\begin{array}{l}\text { Chicken eggs } \\
\text { Swiss chard } \\
\text { Beet greens }\end{array}$ & $\begin{array}{r}16 \\
5 \\
5\end{array}$ & $\begin{array}{l}2.8-4.7 \\
0.6-0.9 \\
1.1-2.5\end{array}$ & $\begin{array}{l}3.8 \\
0.8 \\
1.8\end{array}$ & $\begin{array}{l}3.9-10.0 \\
2.2-4.4 \\
2.0-4.8\end{array}$ & $\begin{array}{r}6.0 \\
2.9 \\
3.0\end{array}$ \\
\hline
\end{tabular}

- The radioactive iron used in these studies was prepared in the atomic pile at Oak Ridge. The specific activity ranged from 455 to $4,237 \mathrm{mc}$. per $\mathrm{gm}$. Fe. and served with the cooking liquid. Eight ounces of orange juice were given with scrambled eggs in a single study.

After iron administration, stools were collected until less than 1 per cent of the oral tracer dose was recovered in a 24-hour collection. Samples of blood were obtained at 2 to 5-day intervals. In most instances, blood samples were obtained until a plateau of constant activity was reached.

The preparation of the collected materials for counting was relatively simple. Water was added to feces in the large collecting bottles, total weight determined, and the mixture homogenized by an Osterizer or an Equipoise shaker. After mixing, three aliquots by weight were transferred to screw cap bottles holding $25 \mathrm{ml}$. of material. Since the quantity of radioiron present in plasma after the first 24 hours was not significant, blood samples were processed for assay by pipetting $25 \mathrm{ml}$. of whole blood into similar bottles. Appropriate standards representing the administered oral dose of radioactive iron salt or food iron were similarly prepared. The standard for iron salts consisted of a portion of the solution taken per mouth by the subjects while that for labeled foods

TABLE III

Recovery of radioiron added to feces

\begin{tabular}{|c|c|c|c|c|}
\hline $\begin{array}{l}\text { Experi- } \\
\text { ment }\end{array}$ & $\begin{array}{c}\text { No. of } \\
\text { stool } \\
\text { samples } \\
\text { ctd. }\end{array}$ & $\begin{array}{l}\text { Net cps } \\
\text { total } \\
\text { stool } \\
\text { (ave.) }\end{array}$ & $\begin{array}{l}\text { Net cps } \\
\text { std. } \\
\text { (ave.) }\end{array}$ & $\begin{array}{c}\% \\
\text { Recovery }\end{array}$ \\
\hline $\begin{array}{l}1 \\
2 \\
3 \\
4\end{array}$ & $\begin{array}{l}8 \\
8 \\
9 \\
9\end{array}$ & $\begin{array}{l}640.63 \\
644.74 \\
668.96 \\
627.90\end{array}$ & $\begin{array}{l}664.4 \\
664.0 \\
662.6 \\
652.3\end{array}$ & $\begin{array}{r}96.42 \\
97.09 \\
100.95 \\
96.25\end{array}$ \\
\hline
\end{tabular}

was made up from weighed aliquots of scrambled eggs or cooked vegetables. These were digested in concentrated nitric acid and diluted to a $25-\mathrm{ml}$. volume in vials like those used for counting the stool and blood samples.

Gamma radiation of the prepared samples was quantitatively measured by Geiger-Mueller counting tubes. Initially, a Sylvania GG306, all metal, bismuth cathode tube was used. This heavily shielded tube was mounted in a horizontal position in a plastic frame and the sample bottles were placed as close as possible beneath the tube, with the long axis of the sample bottle parallel to the tube. Counts were recorded on a Tracerlab Autoscaler. The counting efficiency of this arrangement for $\mathrm{Fe}^{\infty}$ was 0.4 per cent and $180 \mathrm{cps}$ represented 1 microcurie. Statistical analysis of the whole sampling, positioning, and counting technique revealed a potential error that did not exceed \pm 5 per cent.

Later another type of Geiger-Mueller tube was used, the Texas Well Counter. ${ }^{6}$ This tube was approximately 8 to 10 times as sensitive as the GG306. All food absorption studies utilized the Texas Well Counter, counts being recorded by a Berkeley Decimal Scaler.

6 Welch-Allyn Company, Skaneateles, New York. 
The accuracy of the gamma counting methods used for the assay of $\mathrm{Fe}^{\mathrm{\infty}}$ in fecal and blood samples was determined by in vitro recovery experiments. A known quantity of $\mathrm{Fe}^{\mathrm{m}}$ in the form of $\mathrm{FeCl}_{3}$ was added directly to 4 different fecal collections. This material was homogenized, processed as above, and the amount of $\mathrm{Fe}^{\infty}$ present determined by gamma counting techniques. Data obtained were compared with activity observed in a water solution of $\mathrm{Fe}^{\mathrm{s0}}$ counted under identical circumstances. These data are summarized in Table III and reveal that 96 to 101 per cent of the added $\mathrm{Fe}^{50}$ were accounted for in this study. The presence of solid material in feces did not significantly alter the counts recorded.
RESULTS

Absorption of iron by normal subjects (Figures $1,2,3$, and 4)

Figures 1 and 2 reveal a significant difference between the absorption of ferrous chloride and food iron. Recovery results in Figure 1 show approximately 4 to 12 per cent of radioiron were absorbed and incorporated into hemoglobin when $\mathrm{Fe}^{59}$ was administered as ferrous chloride along with 27 to $41 \mathrm{mg}$. of carrier ferrous iron. Sixty-

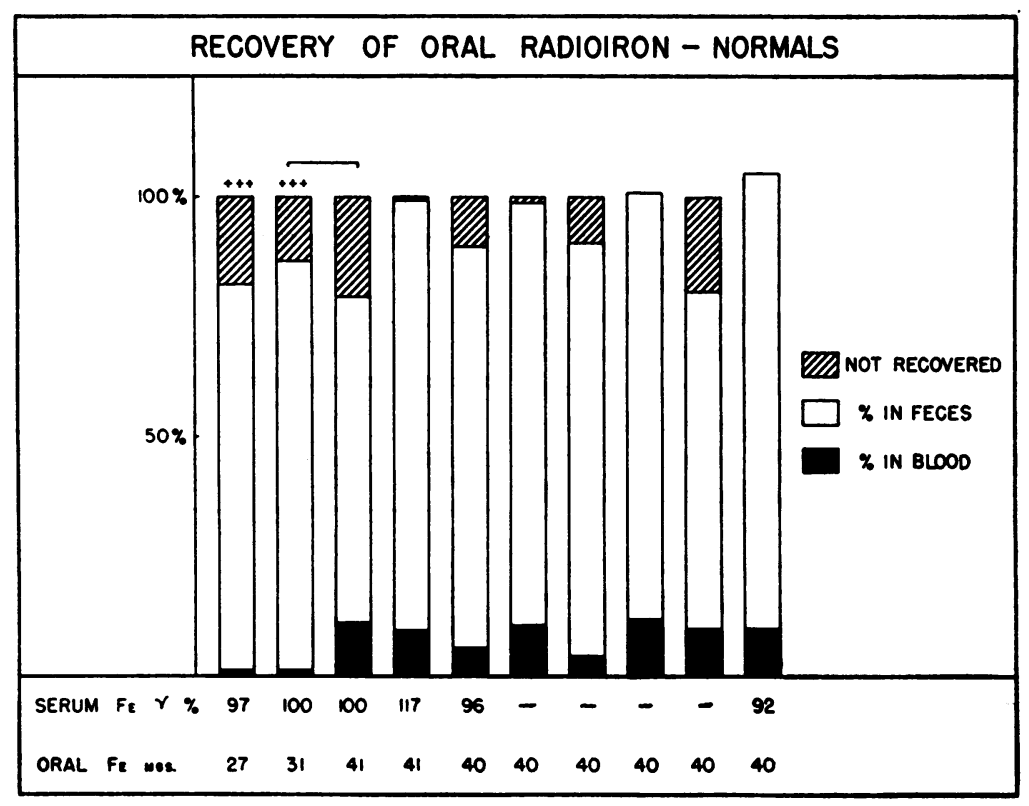

Fig. 1. Recovery of Radiotron by Normal Subjects Following the Oral Administration of an Iron Salt

The labeled salt was administered as ferric chloride ( +++ above column) or as ferrous chloride (no symbol above column) along with 27 to $41 \mathrm{mg}$. of non-radioactive carrier iron. The bracket $\longrightarrow$ indicates multiple studies on a single patient.

It is to be noted that a portion of the oral dose was not recovered (cross hatched area). This unrecovered portion in this figure and in all subsequent figures represents a combination of three factors: absorbed iron not synthesized into hemoglobin but deposited in tissue stores, the error of determinations, and failure by the subject to make absolute quantitative stool collections.

Hematologic values for subjects

$\begin{array}{lcc} & \text { Range } & \text { Mean } \\ \text { Hematocrit (\%) } & 43.0-51.5 & 46.5 \\ \text { Hemoglobin (gm. \%) } & 13.3-16.0 & 14.4 \\ \text { MCHC (\%) } & 28.0-33.0 & 31.9\end{array}$

(MCHC-Mean corpuscular hemoglobin concentration) 


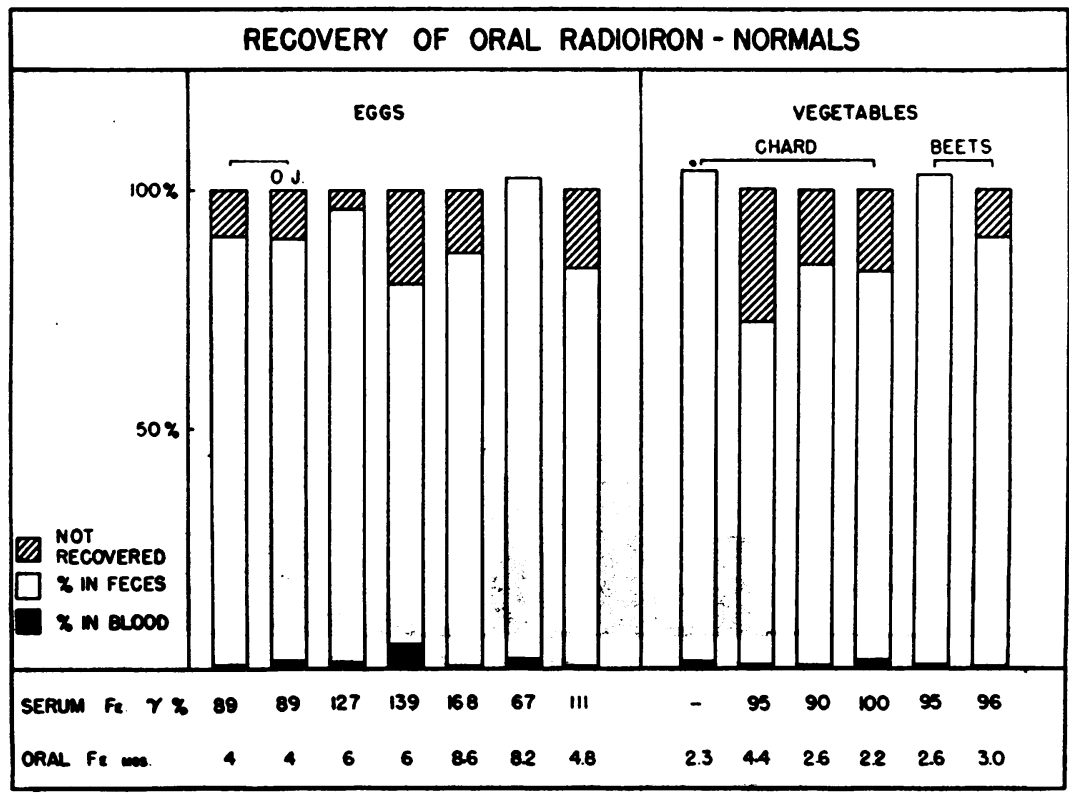

Fig. 2. Recovery of Radiorron by Normal Subjects Following the Administration of a Radiotron Labeled Food Containing from 2.2 to 8.6 Mg. of Non-Radioactive Iron

O. J. (Bar No. 2) indicates 8 ounces of fresh orange juice was administered with the radioiron labeled eggs.

Hematologic values for subjects

$\begin{array}{lcc} & \text { Range } & \text { Mean } \\ \text { Hematocrit (\%) } & 43.0-50.0 & 46.7 \\ \text { Hemoglobin (gm. \%) } & 13.2-15.4 & 14.1 \\ \text { MCHC (\%) } & 29.0-32.0 & 31.0\end{array}$

seven to 96 per cent were recovered in feces and 1 to 22 per cent were not recovered in blood or feces. The percentage of $\mathrm{Fe}^{59}$ incorporated into hemoglobin is indicative of the quantity of carrier iron definitely absorbed and used to form hemoglobin ( 0.9 to $4.6 \mathrm{mg}$.). As the legend to Figure 1 states, the unrecovered percentage of radioiron in this group and in all subsequent groups represents a combination of three factors: absorbed iron not synthesized into hemoglobin but deposited in tissue stores, the error of the determinations, and failure by the subject to make absolutely quantitative collection of stools.

The percentage of absorption and utilization of food iron (Figure 2) was significantly less than that of ferrous chloride even though the amounts of iron given were considerably smaller. With a single exception only 0.5 to 2.3 per cent of egg and vegetable radioiron were incorporated into hemo- globin. In one study 5 per cent of labeled egg iron was used to form hemoglobin. Sixty-five to 99.5 per cent were recovered in the feces and 4 to 28 per cent were not recovered in either the feces or blood. The addition of orange juice in one study did not increase the absorption of egg iron. The percentage of $\mathrm{Fe}^{59}$ absorbed and incorporated into hemoglobin indicated the absorption of from 0.03 to $0.3 \mathrm{mg}$. of the egg or vegetable iron administered. Calculations of the percentage of iron not recovered suggest that as much as 0.3 to $1.3 \mathrm{mg}$. of iron could have been added to tissue stores.

The greater absorption of the iron salt, ferrous chloride, is more apparent when compared with the absorption of similar quantities of ferrous chloride and egg iron (Figure 3). Seven normal subjects, who received $\mathrm{Fe}^{59}$ labeled eggs containing from 4 to $8 \mathrm{mg}$. of iron, absorbed and incorporated 0.5 to 5.0 per cent into hemoglobin, representing 


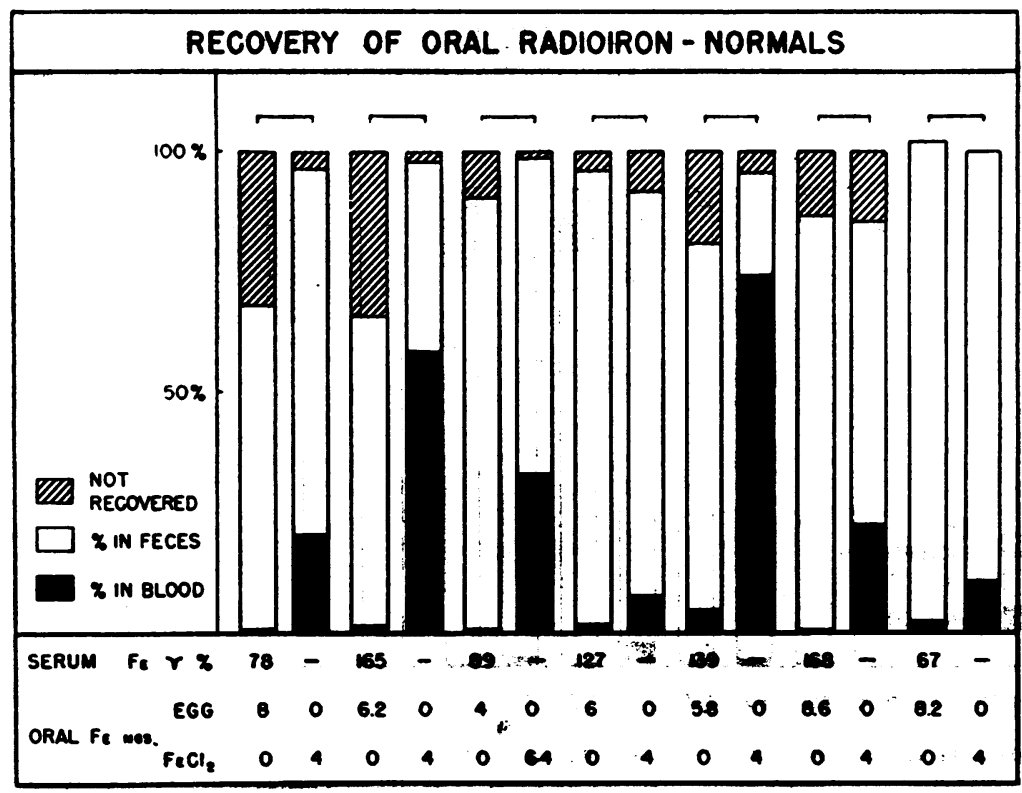

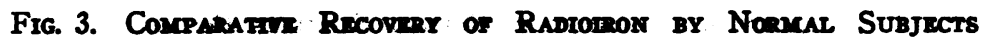
Following the Admernistration of 1) Radiomon Latatud Eggs, aNd 2) a Tracer Dose of Radionctive Ferrous Chlorme

The carrier non-radicactive iron ranged from 4 to $8.6 \mathrm{mg}$.

\begin{tabular}{|ccc}
\multicolumn{3}{c}{ Hematologic values of subjects } \\
& Range & Mean \\
Hematocrit (\%) & $43.0-50.0$ & 45.9 \\
Hemoglobin (gm. \%) & $12.9-15.1$ & 13.6 \\
MCHC (\%) & $27.0-31.0$ & 30.0
\end{tabular}

the absorption of from 0.08 to $0.3 \mathrm{mg}$. of iron. When a similar quantity of ferrous chloride was given, 7.8 to 74.5 per cent of the dose appeared in hemoglobin, representing the absorption of 0.32 to $3.0 \mathrm{mg}$. of iron. The increased absorption and incorporation of this iron salt into hemoglobin ranged from 2 to 100 times that of egg iron.

The effect of egg itself upon the absorption of iron was studied by giving inorganic $\mathrm{Fe}^{\mathrm{s0}}$, as ferrous chloride, to five subjects along with non-labeled scrambled eggs (Figure 4). Under this experimental condition a considerably smaller percentage of iron was absorbed and utilized for hemoglobin formation than when a similar amount of ferrous chloride was administered alone. However, when compared to the absorption and utilization of egg iron, there was usually an appreciably greater absorption and use of the ferrous iron salt even in the presence of eggs. This difference ranged from 1.5 to 10 times the amount of food iron absorbed and incorporated into hemoglobin.
These data as summarized in Table IV indicate that iron in eggs and certain vegetables is not nearly as well absorbed as the iron salt ferrous chloride, and that the concomitant presence of food such as egg may decrease significantly the absorption of the iron salt.

\section{Absorption of iron by subjects with deficient iron stores (Figures 5 and 6)}

Representative results summarized in Figure 5 show that with one exception more than 20 per cent of the iron was absorbed and incorporated into hemoglobin when $\mathrm{Fe}^{\mathrm{so}}$ was administered as ferrous or ferric chloride. Nearly all of the remaining radioiron was recovered in the stools except in a single patient with a complicating chronic infection (Figure 5, Studies 7 and 8).

The absorption of $\mathrm{Fe}^{\mathrm{sp}}$ labeled food by subjects with deficient iron stores is summarized in Figure 6. Food iron was not as well absorbed as iron 


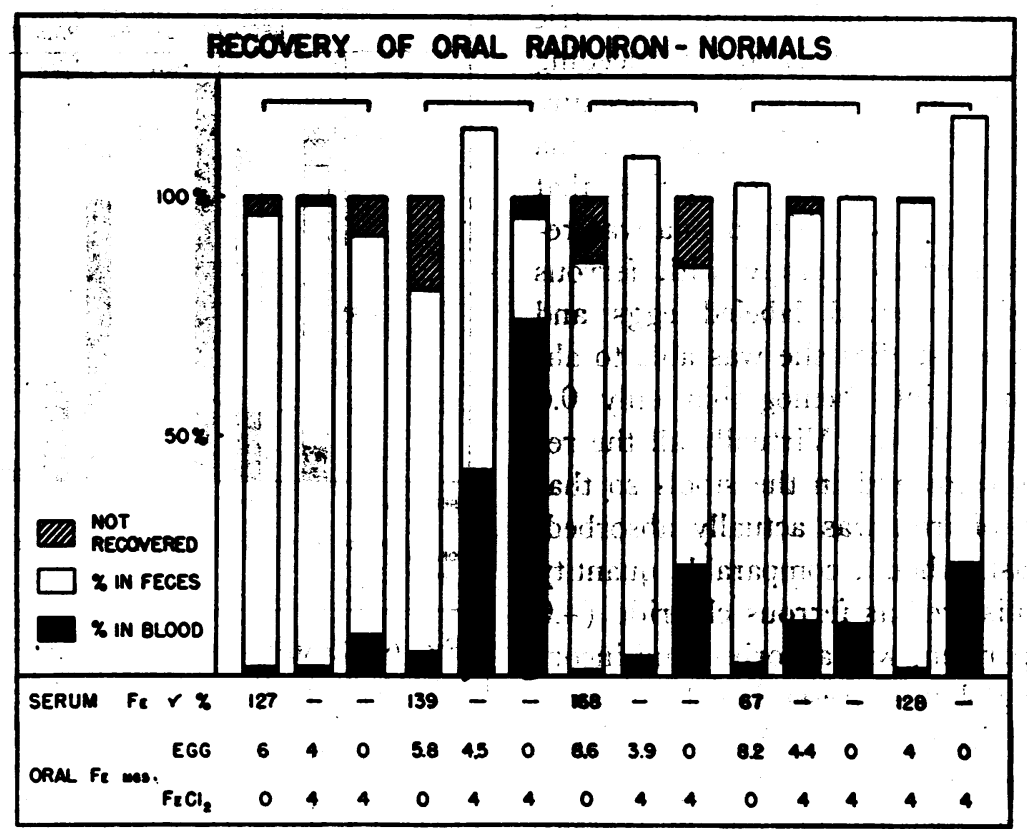

Fig. 4. The Comparative Recovery of Radiotron by Normal Subjects Following the Administration of 1) a Single Ferding of Radiorron Labeled Eggs, 2) a Combined Feeding of Radionctive Ferrous Chloride and Non-Labeled Egcs, and 3) a Tracer Dose of Radioactive Ferrous ChLORIDE

The carrier non-radioactive iron ranged from 4 to $8.6 \mathrm{mgs}$.

Hematologic values of subjects

\section{Hematocrit (\%) Hemoglobin ( $\mathrm{gm}$. \%) MCHC (\%)}

administered as ferrous chloride. Iron-deficient subjects receiving $\mathrm{Fe}^{50}$ labeled chicken eggs absorbed and utilized 10.3, 20.5, and 0.6 per cent of $\mathrm{Fe}^{50}$, while those receiving $\mathrm{Fe}^{\mathrm{s}}$ labeled vegetables absorbed and utilized 3.6 and 30 per cent. Most of the remaining $\mathrm{Fe}^{\mathrm{s}}$ not appearing in hemoglobin was recovered in the stools.

TABRE IV

Per cent of radioiron incorporated into hemoglobin in normal subjects

\begin{tabular}{|c|c|c|c|c|c|}
\hline \multirow{2}{*}{ Form of } & \multirow{2}{*}{$\begin{array}{l}\text { No. of } \\
\text { etudies }\end{array}$} & \multirow{2}{*}{$\begin{array}{c}\text { Oral doose } \\
\text { (me.) }\end{array}$} & \multicolumn{3}{|c|}{ Per cent in hemodobin } \\
\hline & & & Rance & Mean & Median \\
\hline $\begin{array}{l}\mathrm{FeCl} \\
\mathrm{FeCl}_{2} \\
\mathrm{FeCl}_{2} \\
\mathrm{Egg}+\mathrm{FeCl}_{2} \\
\text { Egg } \\
\text { Swiss chaird } \\
\text { Beet greens }\end{array}$ & $\begin{array}{r}2 \\
12 \\
8 \\
5 \\
5 \\
14 \\
4 \\
2\end{array}$ & $\begin{array}{r}27.0-31.0 \\
20.0-41.0 \\
4.0-6.4 \\
7.9-8.4 \\
4.0-8.6 \\
2.3-4.4 \\
2.6-3.0\end{array}$ & $\begin{array}{l}0.8-0.9 \\
3.9-11.6 \\
7.8-74.5 \\
1.3-43.2 \\
0.5-5.0 \\
0.8-1.6 \\
0.8-0.9\end{array}$ & $\begin{array}{r}0.85 \\
8.73 \\
31.40 \\
12.60 \\
1.40 \\
1.20 \\
0.85\end{array}$ & $\begin{array}{r}0.85 \\
9.80 \\
23.25 \\
3.90 \\
0.60 \\
1.25 \\
0.85\end{array}$ \\
\hline
\end{tabular}

$\begin{array}{cc}\text { Range } & \text { Mean } \\ 44.0-51.0 & 47.3 \\ 12.7-15.1 & 14.0 \\ 29.0-32.0 & 30.0\end{array}$

The quantity of carrier iron absorbed and incorporated into hemoglobin by patients with deficient iron stores ranged from $1.0 \mathrm{mg}$. when 2 to $10 \mathrm{mg}$. of food iron were given, to from 4.8 to $18.5 \mathrm{mg}$. when 31 to $80 \mathrm{mg}$. of iron were administered as ferrous or ferric chloride. These figures cannot be compared since similar quantities of iron were not administered. However, iron-deficient patients absorbed a much larger percentage of food iron than did normal subjects who received a similar quantity of food iron.

Multiple studies were carried out on two irondeficient subjects to compare the absorption of ferrous chloride and labeled food. One patient (Figure 6, Studies 2 and 3) absorbed 20 per cent of $\mathrm{Fe}^{\mathrm{s0}}$ incorporated in eggs and 100 per cent of a comparable dose ( $5.0 \mathrm{mg}$.) of ferrous chloride. The second patient (Figure 6, Studies 4 through 
7) was a female who had had a subtotal gastric resection three years previously for a bleeding ulcer. Subsequent to this operative procedure she developed a profound iron deficiency anemia in the absence of further bleeding other than that associated with her menses. This anemia was reported to be refractory to therapy with ferrous sulfate. When she received labeled eggs and chard in two separate studies she was able to absorb and incorporate into hemoglobin only 0.6 and 3 per cent, respectively. Virtually all the remaining $\mathrm{Fe}^{59}$ was recovered in the stools so that less than $0.1 \mathrm{mg}$. of iron was actually absorbed. In striking contrast, when a comparable quantity of $\mathrm{Fe}^{59}$ was administered as ferrous chloride (4.0 mg. of iron), 88 per cent was absorbed and incorporated into hemoglobin, representing the absorption of $3.5 \mathrm{mg}$. of iron. When the carrier dose of ferrous chloride was increased to approximate the $80 \mathrm{mg}$. of iron received daily on an average therapeutic regimen of ferrous sulfate, 32 per cent of the dose was absorbed and incorporated into

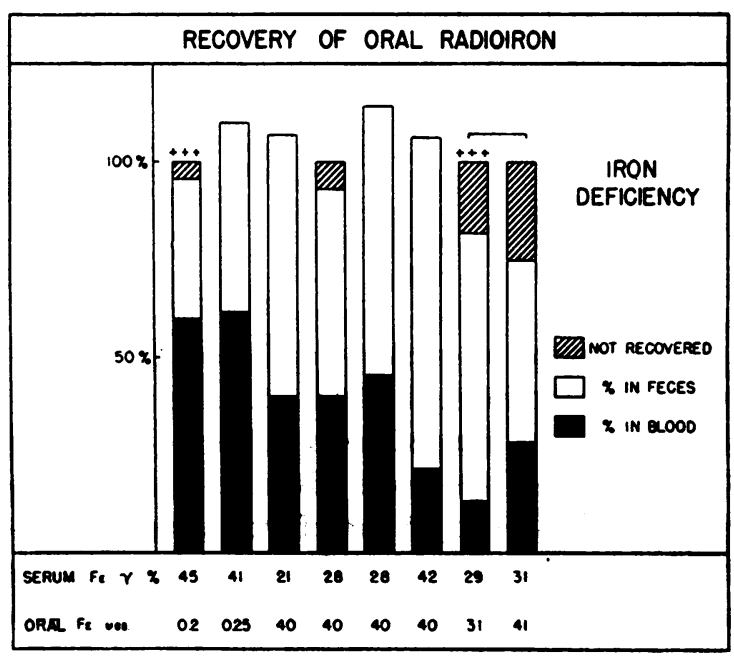

Fig. 5. Recovery of Radiorron by Patients with Deficient Iron Stores Following the Administration OF AN IRON SALT

The labeled salt was administered as ferric chloride (+++ above column) or as ferrous chloride (no symbol above column) with 31 to $41 \mathrm{mg}$. of carrier iron. No carrier iron was administered in studies 1 and 2.

Hematologic values of patients

$\begin{array}{lrr} & \text { Range } & \text { Mean } \\ \text { Hematocrit (\%) } & 21.1-44.0 & 20.8 \\ \text { Hemoglobin }(\mathrm{gm} . \%) & 5.0-13.0 & 8.4 \\ \text { MCHC (\%) } & 22.4-30.0 & 27.0\end{array}$

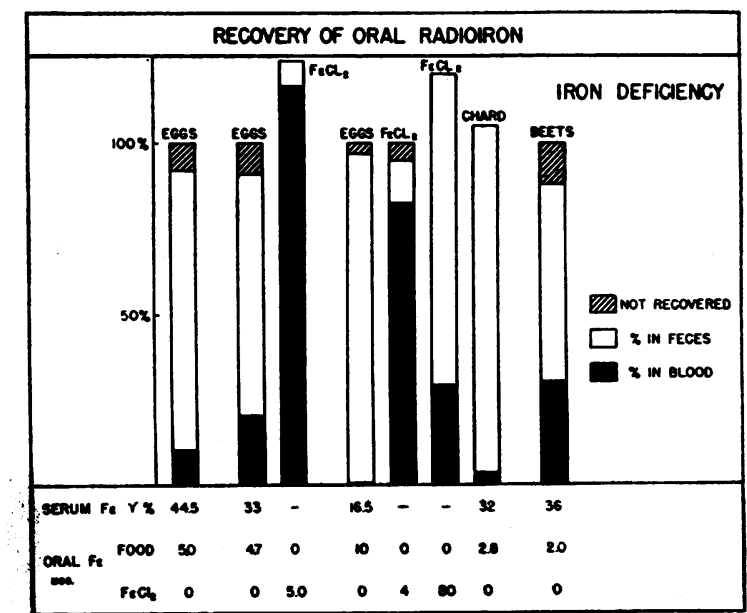

Fig. 6. Comparative Recovery of Radiotron BY Iron-Deficient Patients Following the Administration of Either Labeled FoOd (EgGs, Vegetables) or Ferrous Chloride

Studies 2 and 3 were carried out in sequence on one patient and studies 4 to 7 inclusive on a second patient.

Hematologic values of patients

$\begin{array}{lrr} & \text { Range } & \text { Mean } \\ \text { Hematocrit (\%) } & 29.0-40.0 & 32.0 \\ \text { Hemoglobin (gm. \%) } & 6.0-11.9 & 7.5 \\ \text { MCHC (\%) } & 19.0-30.0 & 23.0\end{array}$

hemoglobin, representing the absorption of $26 \mathrm{mg}$. of iron.

In summary, iron as ferrous chloride is absorbed in larger quantity by iron-deficient subjects than is the iron in eggs and vegetables. However, food iron is absorbed and used to a much greater extent by patients with iron deficiency than by normal subjects.

\section{Absorption of iron by subjects with excess iron stores (Figures 7 and 8).}

Sixteen absorption studies have been performed on 9 patients with the excess iron stores of idiopathic hemochromatosis. Seven of these patients were males and two ${ }^{7}$ were females past the menopause. The comparative absorption of ferrous chloride and $\mathrm{Fe}^{50}$ labeled eggs was evaluated in one patient with hemochromatosis. The absorption of iron before and after an intensive venesection program was measured in one patient with

\footnotetext{
7 We wish to thank Drs. Alexander Marble and Frank Gardner, Boston, Massachusetts, for the opportunity to study these patients.
} 
hemochromatosis, and only after venesection in another.

It is evident from Figure 7 that patients with well-established, untreated idiopathic hemochromatosis of long duration, with elevated serum iron levels and saturated iron stores did not absorb either ferrous chloride or food iron to any greater extent than did normal subjects studied under similar conditions. Patients with hemochromatosis absorbed and incorporated into hemoglobin 0.5 to 11.1 per cent of $\mathrm{Fe}^{59}$ administered as ferrous chloride. This represented the absorption of 0.1 to $3.3 \mathrm{mg}$. of the 24 to $41 \mathrm{mg}$. of carrier iron administered. Almost all of the remaining iron was recovered in the feces. Additional iron beyond that incorporated into hemoglobin may have been absorbed by the two female patients studied (Figure 7 , Studies 7 and 8). The total quantity of iron possibly absorbed by these two female subjects was 28 and 29.7 per cent, or approximately $11 \mathrm{mg}$. of iron by each patient.

Absorption of food iron by untreated patients with hemochromatosis was evaluated in two patients who received $\mathrm{Fe}^{59}$ labeled beet greens containing 2.8 and $4.8 \mathrm{mg}$. of iron (Figure 7). Only 1.0 and 1.1 per cent of iron was absorbed and incorporated into hemoglobin. This represents absorption of a quantity of food iron which is essentially the same as that obtained in normal sub-

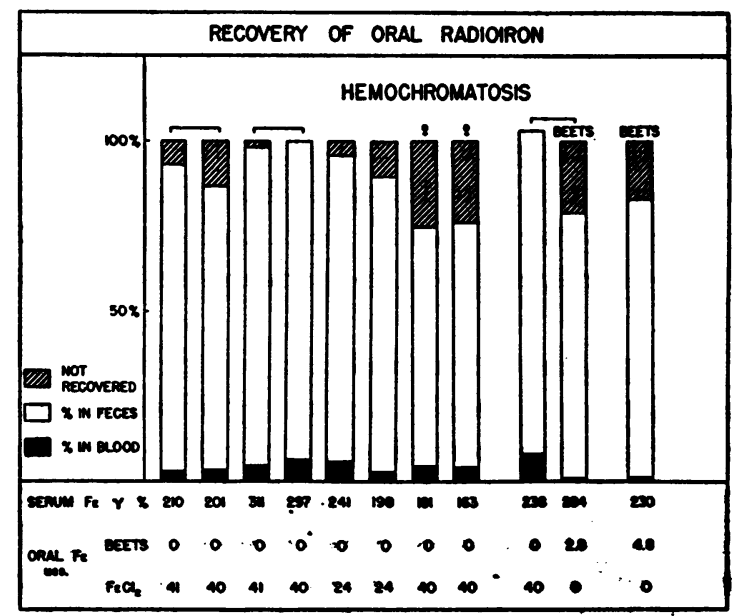

Fig. 7. Recovery of Radioiron in Patients with Hemochromatosis Following Administration of Ferrous Chloride or Labeled Beets

These patients had not been venesected. The symbol $q$ identifies a female patient.

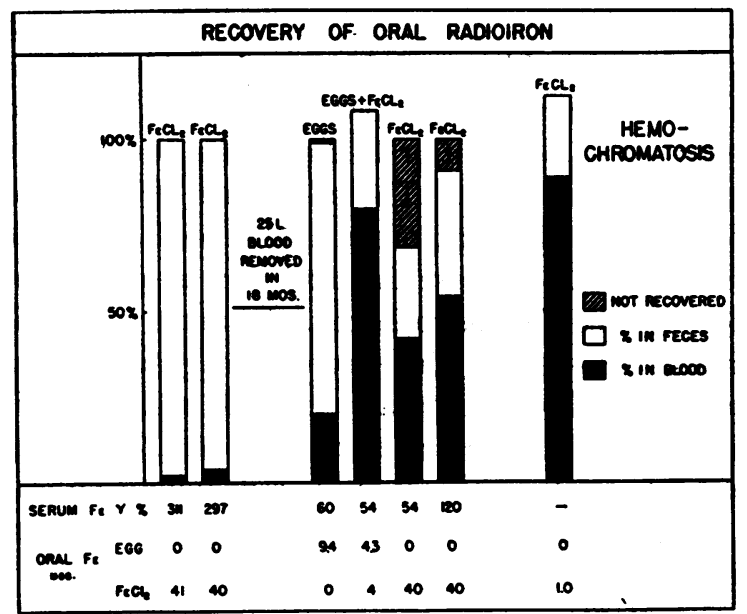

Fig. 8. Recovery of RadioIron Before and after Intensive Venesection Therapy of a Patient with Hemochromatosis (Studies 1 Through 6)

Recovery was measured in a second patient (study 7) only after multiple venesections.

jects. If all the unrecovered iron was absorbed and deposited in tissue, the total absorption could be increased to 22 and 18.1 per cent, or 0.6 and $0.9 \mathrm{mg}$. of iron.

Absorption of $\mathrm{Fe}^{59}$ labeled eggs was not evaluated in any untreated patient with hemochromatosis. However, such a study was completed in one subject with hemochromatosis after the removal of 25 liters of blood over an 18-month period (Figure 8). Multiple iron absorption studies were completed before and after the venesection program. Initially the serum iron ranged between 235 and 311 micrograms per $100 \mathrm{ml}$. When studied at this stage he absorbed and incorporated into hemoglobin 4.7 to 6.2 per cent of a $40-\mathrm{mg}$. dose of ferrous chloride. Ninety-four per cent of the dose was recovered in stools. After extensive venesections, during which period his hemoglobin remained at essentially normal levels and approximately $13 \mathrm{gm}$. of iron were removed from his stores, his serum iron was reduced to 60 micrograms per $100 \mathrm{ml}$. At this time he absorbed and used 20.2 per cent of $9.4 \mathrm{mg}$. of food iron, equivalent to the absorption of $1.9 \mathrm{mg}$. of iron. This result approximates closely that obtained in subjects with iron deficiency who received labeled eggs. In contrast, when $\mathrm{Fe}^{\mathrm{si}}$ was administered as ferrous chloride along with nonradioactive eggs, he absorbed and incorporated 
into hemoglobin 80.4 per cent, or $6.7 \mathrm{mg}$. of an $8.3 \mathrm{mg}$. dose of iron. Subsequently, with a serum iron of 54 micrograms per $100 \mathrm{ml}$. he absorbed and used 42 per cent or $15.2 \mathrm{mg}$. of a $40-\mathrm{mg}$. dose of ferrous chloride. The additional 30 per cent not recovered, if absorbed and added to tissue stores, would increase the total iron absorbed under these conditions to $29 \mathrm{mg}$. Without any additional venesections the serum iron gradually increased to 120 micrograms per $100 \mathrm{ml}$. At this time he absorbed and used 54.5 per cent, or $22 \mathrm{mg}$. of a 40-mg. dose. Most of the remaining iron was recovered in the feces except for 9 per cent, some of which may have been absorbed and deposited in tissue stores.

A second patient with hemochromatosis was studied only after extensive venesections. ${ }^{8} \mathrm{He}$ received $\mathrm{Fe}^{59}$ without added carrier iron, and absorbed and utilized 88.5 per cent of the administered iron for the formation of hemoglobin. The remainder was recovered in stools.

In summary, neither beet iron nor the iron salt, ferrous chloride, is absorbed to any demonstrably greater extent by patients with well-established untreated hemochromatosis than by normal subjects. An intensive venesection program will significantly lower the serum iron and remove iron from the body stores. Under these circumstances, absorption of both ferrous chloride and egg iron is greatly increased, approximating that usually encountered in iron-deficient subjects.

\section{DISCUSSION}

Our studies indicate that normal subjects, irondeficient patients, and patients with idiopathic hemochromatosis absorb ferrous chloride more readily than food iron. In many of these studies a solution of ferrous chloride was administered to the subject in a quantity that considerably exceeded the amount of iron usually eaten by an individual in a single average meal. Chemical or physical substances that might decrease iron absorption were excluded since the patients were fasting. In most cases a supplementary reducing agent such as ascorbic acid was given with the ferrous chloride. There is evidence that the administration of ascorbic acid may increase the absorp-

8 This subject was studied through the cooperation of Dr. Wayne Rundles, Duke University School of Medicine. tion of ferrous iron salts (19). However, in the present study there was no apparent difference between the absorption of iron by 7 subjects ${ }^{9}$ who did not receive supplementary ascorbic acid and comparable subjects who received this reducing agent with ferrous chloride. No systematic comparison was made of the absorption of ferrous iron salts administered to the same patient with and without a reducing agent.

Iron in considerable excess of the daily loss of 1 mg. may be absorbed when ferrous chloride is administered to normal subjects under the described experimental conditions. These results agree with those reported by Dubach, Callender, and Moore (27). Within the limitations imposed by inaccuracies in stool collection our data may be interpreted as lending support to their suggestion that normal subjects may absorb and deposit in tissue stores additional iron beyond that which is incorporated into hemoglobin.

Normal subjects absorbed much less iron after a single feeding of radioiron labeled eggs or vegetables. These observations were obtained under physiological conditions more closely approximating the ingestion of an average meal containing 5 mg. of iron. Only $0.3 \mathrm{mg}$. of iron at best, or approximately one-third of the daily iron requirement was absorbed and incorporated into hemoglobin. This observation agrees with previously reported studies (26). Although fecal recovery data suggest that additional iron in food may possibly be absorbed and deposited in body stores, the limited absorption of food iron observed supports the suggestion (26) that the daily adult requirement of 12 to $15 \mathrm{mg}$. of dietary iron recommended by the National Research Council (32) may be barely sufficient to maintain the body iron stores.

The present studies indicate that patients with iron deficiency usually absorb significantly more food iron than normal subjects. However, the amount of iron absorbed from food was not much greater than the quantity lost daily from the body in the absence of bleeding or pregnancy. Moore and Dubach, on the other hand, found only a few iron-deficient subjects who absorbed more food

9 These 7 subjects include 5 normal subjects, 1 irondeficient patient, and 1 patient with idiopathic hemochromatosis. 
iron than did normal individuals, although the coadministration of a reducing substance such as ascorbic acid significantly increased the quantity of iron absorbed (26). In our studies markedly limited absorption of food iron was observed in an iron-deficient patient with a subtotal gastrectomy. Iron as ferrous chloride was as readily absorbed by this patient as by the other iron-deficient patients. Partial gastrectomy may have influenced the absorption of food iron since there is some evidence that dietary iron is ionized, reduced to the ferrous form, and better absorbed at an acid $\mathrm{pH}(33-37)$.

The limited absorption of food iron in these studies suggests that it would be difficult for an iron-deficient patient to replenish his stores by diet alone. Supplementary medicinal iron seems indicated for individuals who undergo chronic blood loss, have increased physiological requirements, or have an absorptive defect due to an operative procedure, e.g., subtotal gastrectomy, or steatorrhea $(7,26,38,39)$. Therapy should be continued after the hemoglobin level has been restored to normal since it has been shown that depleted iron stores are not easily reconstituted (40).

A different situation is observed in hemochromatosis. Although our studies indicate that neither ferrous chloride nor food iron is absorbed to any greater extent in well-established hemochromatosis than in normal subjects, it appears necessary to assume that excess iron must be absorbed during the developmental phase of this disease. By no other means can one satisfactorily explain the huge iron stores found in a patient with idiopathic hemochromatosis. This assumption is perhaps supported by our observation that absorption of both ferrous chloride and food iron was markedly increased in patients with hemochromatosis after they had undergone an intensive venesection program. After 12 to 15 grams of iron had been removed by weekly or biweekly $500-\mathrm{ml}$. venesections, the absorption of iron was approximately that seen in iron deficiency. It is significant that this increased absorption was observed even after the serum iron concentration had returned to normal (120 micrograms per $100 \mathrm{ml}$.).

Studies showing increased radioiron absorption in younger patients with hemochromatosis have been reported recently which lend support to the concept that iron absorption must be increased during the developmental stage of idiopathic hemochromatosis (41-43). External measurements indicated most of the absorbed iron was stored in the liver $(43,44)$. Increased absorption of a lesser degree has also been observed in three older female patients (43). Of 9 patients with hemochromatosis in our studies, the two women were the only patients who appeared to absorb an increased quantity of iron. Menstrual loss of blood may have had an effect similar to that of repeated, small venesections, so that full development of the disorder was delayed. Our studies after venesection as well as those of Peterson and Ettinger (41) do show that extensive blood loss will modify the absorption of iron even after hemochromatosis has fully developed. Increased absorption may then occur even with a normal serum iron concentration. These results suggest iron stores may reaccumulate in idiopathic hemochromatosis unless vensections are continued at intervals as recommended by Finch and Finch (45).

Although the present study has demonstrated greater absorption of iron salts than of food iron, it does not provide a clear explanation why this occurs. Multiple studies in normal subjects evaluating the comparative absorption of labeled egg iron and of ferrous chloride alone and with nonlabeled eggs suggest that the presence of egg will decrease the absorption of the iron salt. This decreased absorption may be related to the solid content of the test meal (46), or formation of an insoluble compound of iron with a chemical constituent of egg or bread. Hegsted, Finch, and Kinney (47) have shown that a high concentration of added phosphate will decrease absorption of iron by rats on a corn grit diet, presumably by formation of an insoluble iron phosphate. Similarly, soluble phytates may also interfere with iron absorption $(46,48)$. Conversely, rats on a corn grit diet with added iron will absorb large amounts of iron and produce progressive hemosiderosis of the tissues (49). Studies by Hegsted, Finch, and Kinney indicate that the low level of dietary phosphate attained with a corn grit diet was primarily responsible for increased absorption of iron (47). Such increased absorption of iron observed on a phosphate-deficient diet with excess iron might account for development of dietary hemosiderosis 
observed in malnourished pellagrins in South Africa $(50,51)$.

The influence of phosphates on iron absorption may explain the present observations that egg iron was poorly absorbed and that addition of egg decreased absorption of ferrous chloride. Halkett, Peters, and Ross found that egg yolk iron is in the ferric state and is strongly complexed to the phosphate of yolk phosphoproteins (52). Formation of such an iron phosphate complex occurs both in the biological production of eggs and when iron is added to eggs in vitro. They further observed that egg yolk iron is not removed by peptic digestion and acidity unless a reducing agent is present. It appears egg iron is not readily available for absorption and it is not surprising that so little was absorbed in the present study as well as in previous animal studies (53). In contrast it has been shown that a 10 to 20 fold increase in the absorption of food (egg) iron generally occurs in iron-deficient subjects when large amounts of ascorbic acid are administered with the iron (7, 26). This effect is presumably dependent upon the reduction of iron to the ferrous form and may be accomplished by other reducing substances in food.

It is of interest to consider how results of the present studies may relate to the theory that the intestinal mucosa is an important regulator of iron absorption $(24,54-57)$. According to Granick (56), iron is transferred from the intestinal lumen to blood by a protein, apoferritin, present in cells of the intestinal mucosa. Iron is taken up by the mucosal cells until all apoferritin is converted to ferritin. No more iron may then be absorbed until ferritin has given up iron to plasma. This is the concept of the "mucosal block" originally suggested by Hahn, Bale, Ross, Balfour, and Whipple (24).

Dubach, Callender, and Moore (27) have presented evidence that this block is at best a partial one and that in certain conditions, such as refractory anemia, pernicious anemia in relapse, or hemolytic anemia, the mucosal block does not prevent iron from being absorbed in spite of adequate body iron stores. We have observed a similar increase in iron absorption in thalassemia minor and in renal anemia (44). Moreover, it would appear that the block must fail significantly during the developmental stage of idiopathic hemochromato- sis and again in this disease after an extensive course of phlebotomies. Other examples of the alteration of the mucosal block in animals and men have been discussed previously in relation to factors that influence absorption of iron.

Finally, our data in normal subjects, as well as those of others (27) suggest that the "mucosal block" does not prevent absorption of an increased quantity of iron salt when it is administered in a single feeding to a fasting subject under optimal conditions, i.e., as a solution of ferrous chloride with ascorbic acid, or when given in large quantities (4). Such excess iron absorption has also been observed after average doses of iron salts have been orally administered for a period of years $(58,59)$.

\section{SUM MARY AND CONCLUSIONS}

1. The iron salt, ferrous chloride, is absorbed far more readily and in greater quantity by normal subjects and by patients with deficient and excess iron stores than is iron present in certain foods (eggs, vegetables).

2. Egg and vegetable iron are not absorbed sufficiently to supply iron in the face of increased loss or increased physiological requirements.

3. Absorption of certain food iron and ferrous chloride in patients with well-established hemochromatosis is approximately equal to that observed in normal subjects. However, it can be assumed that excess quantities of iron must be absorbed during the developmental phase of this disease.

4. After removal of blood by multiple venesections absorption of ferrous chloride and egg iron by patients with idiopathic hemochromatosis is markedly increased.

5. Absorption of iron salts is significantly influenced by dietary factors which may modify the form and solubility of iron in the lumen of the gastrointestinal tract.

6. Further evidence has been presented to support previous data in the literature which indicated that the "mucosal block" to iron absorption is only relatively complete and may not uniformly prevent the excess accumulation of iron in the body.

\section{ACKNOWLEDGMENTS}

We wish to express our appreciation to Mrs. Mary Pratt, Miss Joan Donovan, Mr. John Sullivan, and Mrs. Margaret Jewell for their technical assistance. 


\section{REFERENCES}

1. Hahn, P. F., Bale, W. F., Hettig, R. A., Kamen, M. D., and Whipple, G. H., Radioactive iron and its excretion in urine, bile, and feces. J. Exper. Med., 1939, 70, 443.

2. McCance, R. A., and Widdowson, E. M., The absorption and excretion of iron following oral and intravenous administration. J. Physiol., 1938, 94, 148.

3. Copp, D. H., and Greenberg, D. M., A tracer study of iron metabolism with radioactive iron. I. Methods: Absorption and excretion of iron. J. Biol. Chem., 1946, 164, 377.

4. Brock, J. F., and Hunter, D., The fate of large doses of iron administered by mouth. Quart. J. Med., 1937, n.s., 6, 5.

5. Welch, C. S., Wakefield, E. G., and Adams, M., Function of the large intestine of man in absorption and excretion. Study of a subject with an ileostomy stoma and an isolated colon. Arch. Int. Med., 1936, 58, 1095.

6. Stewart, W. B., Snowman, R. T., Yuile, C. L., and Whipple, G. H., Radioiron excretion by the skin and kidney of dogs. Proc. Soc. Exper. Biol. \& Med., 1950, 73, 473.

7. Moore, C. V., The importance of nutritional factors in the pathogenesis of iron-deficiency anemia. Am. J. Clin. Nutrition, 1955, 3, 3.

8. Dubach, R., Moore, C. V., and Callender, S., Studies in iron transportation and metabolism. IX. The excretion of iron as measured by the isotope technique. J. Lab. \& Clin. Med., 1955, 45, 599.

9. Johnston, F. A., McMillan, T. J., and Evans, E. R., Perspiration as a factor influencing the requirement for calcium and iron. J. Nutrition, 1950, 42, 285.

10. Ingalls, R. L., and Johnston, F. A., Iron from gastrointestinal sources excreted in the feces of human subjects. J. Nutrition, 1954, 53, 351.

11. Little, A. G., Jr., Power, M. H., and Wakefield, E. G., Absorption and excretion of iron. Ann. Int. Med., 1945, 23, 627.

12. Schlaphoff, D., and Johnston, F. A., The iron requirement of six adolescent girls. J. Nutrition, 1949, 39, 67.

13. Johnston, F. A., Frenchman, R., and Boroughs, E. D., The absorption of iron from beef by women. J. Nutrition, 1948, 35, 453.

14. Johnston, F. A., Frenchman, R., and Boroughs, E. D., The iron metabolism of young women on two levels of intake. J. Nutrition, 1949, 38, 479.

15. McMillan, T. J., and Johnston, F. A., The absorption of iron from spinach by six young women, and the effect of beef upon the absorption. J. Nutrition, 1951, 44, 383.

16. Widdowson, E. M., and McCance, R. A., Iron exchanges of adults on white and brown bread diets. Lancet, 1942, 1, 588.
17. Widdowson, E. M., and McCance, R. A., The absorption and excretion of iron before, during, and after a period of very high intake. Biochem. J., 1937, 31, 2029.

18. Leverton, R. M., Iron metabolism in human subjects on daily intakes of less than 5 milligrams. J. Nutrition, 1941, 21, 617.

19. Moore, C. V., Arrowsmith, W. R., Welch, J., and Minnich, V., Studies in iron transportation and metabolism. IV. Observations on the absorption of iron from the gastro-intestinal tract. J. Clin. Invest., 1939, 18, 553.

20. Heath, C. W., Strauss, M. B., and Castle, W. B., Quantitative aspects of iron deficiency in hypochromic anemia (The parenteral administration of iron). J. Clin. Invest., 1932, 11, 1293.

21. Heath, C. W., Oral administration of iron in hypochromic anemia. Arch. Int. Med., 1933, 51, 459.

22. Hahn, P. F., Bale, W. F., Lawrence, E. O., and Whipple, G. H., Radioactive iron and its metabolism in anemia. Its absorption, transportation, and utilization. J. Exper. Med., 1939, 69, 739.

23. Hahn, P. F., Ross, J. F., Bale, W. F., and Whipple, G. H., The utilization of iron and the rapidity of hemoglobin formation in anemia due to blood loss. J. Exper. Med., 1940, 71, 731.

24. Hahn, P. F., Bale, W. F., Ross, J. F., Balfour, W. M., and Whipple, G. H., Radioactive iron absorption by gastro-intestinal tract. Influence of anemia, anoxia, and antecedent feeding. Distribution in growing dogs. J. Exper. Med., 1943, 78, 169.

25. Balfour, W. M., Hahn, P. F., Bale, W. F., Pommerenke, W. T., and Whipple, G. H., Radioactive iron absorption in clinical conditions: Normal, pregnancy, anemia, and hemochromatosis. J. Exper. Med., 1942, 76, 15.

26. Moore, C. V., and Dubach, R., Observations on the absorption of iron from foods tagged with radioiron. Tr. A. Am. Physicians, 1951, 64, 245.

27. Dubach, R., Callender, S. T. E., and Moore, C. V., Studies in iron transportation and metabolism. VI. Absorption of radioactive iron in patients with fever and with anemias of varied etiology. Blood, 1948, 3, 526.

28. Dubach, R., Moore, C. V., and Minnich, V., Studies in iron transportation and metabolism. V. Utilization of intravenously injected radioactive iron for hemoglobin synthesis, and an evaluation of the radioactive iron method for studying iron absorption. J. Lab. \& Clin. Med., 1946, 31, 1201.

29. Kitzes, G., Elvehjem, C. A., and Schuette, H. A., The determination of blood plasma iron. J. Biol. Chem., 1944, 155, 653.

30. Ross, J. F., Chodos, R. B., Baker, W. H., and Freis, E. D., The blood volume in congestive heart failure. Tr. A. Am. Physicians, 1952, 65, 75.

31. Halkett, J. A. E., Chodos, R. B., and Ross, J. F., Unpublished data. 
32. National Research Council. Recommended dietary allowances. Reprint and Circular Series No. 129, 1948.

33. Mettier, S. R., and Minot, G. R., The effect of iron on blood formation as influenced by changing the acidity of the gastroduodenal contents in certain cases of anemia. Am. J. M. Sc., 1931, 181, 25.

34. Kellogg, F., and Mettier, S. R., Effect of alkaline therapy for peptic ulcer on utilization of dietary iron in the regeneration of hemoglobin. Arch. Int. Med., 1936, 58, 278.

35. Barer, A. P., and Fowler, W. M., Influence of gastric acidity and degree of anemia on iron retention. Arch. Int. Med., 1937, 59, 785.

36. Mettier, S. R., Kellogg, F., and Rinehart, J. F., Chronic idiopathic hypochromic anemia. Etiologic relationship of achlorhydria to the anemia, with special reference to the effect of large doses of iron, organic (dietary) iron and of predigested food upon the formation of erythrocytes. Am. J. M. Sc., 1933, 186, 694.

37. Gubler, C. J., Absorption and metabolism of iron. Science, 1956, 123, 87.

38. Owren, P. A., The pathogenesis and treatment of iron deficiency anemia after partial gastrectomy. Acta chir. Scandinav., 1952, 104, 206.

39. Badenoch, J., and Callender, S. T., Iron metabolism in steatorrhea. The use of radioactive iron in studies of absorption and utilization. Blood, 1954, 9, 123.

40. Haskins, D., Stevens, A. R., Jr., Finch, S., and Finch, C. A., Iron metabolism. Iron stores in man as measured by phlebotomy. J. Clin. Invest., 1952, 31, 543.

41. Peterson, R. E., and Ettinger, R. H., Radioactive iron absorption in siderosis (hemochromatosis) of the liver. Am. J. Med., 1953, 15, 518.

42. Alper, T., Savage, D. V., and Bothwell, T. H., Radioiron studies in a case of hemochromatosis. J. Lab. \& Clin. Med., 1951, 37, 665.

43. Bothwell, T. H., van Doorn-Wittkampf, H. van W., Du Preez, M. L., and Alper, T., The absorption of iron. Radioiron studies in idiopathic hemochromatosis, malnutritional cytosiderosis, and transfusional hemosiderosis. J. Lab. \& Clin. Med., 1953, 41, 836.

44. Chodos, R. B., and Ross, J. F., Unpublished data.
45. Finch, S. C., and Finch, C. A., Idiopathic hemochromatosis, an iron storage disease. A. Iron metabolism in hemochromatosis. Medicine, 1955, 34, 381.

46. Sharpe, L. M., Peacock, W. C., Cooke, R., and Harris, R. S., The effect of phytate and other food factors on iron absorption. J. Nutrition, 1950, 41, 433.

47. Hegsted, D. M., Finch, C. A., and Kinney, T. D., The influence of diet on iron absorption. II. The interrelation of iron and phosphorus. J. Exper. Med., 1949, 90, 147.

48. McCance, R. A., Edgecombe, C. N., and Widdowson, E. M., Phytic acid and iron absorption. Lancet, 1943, 2, 126.

49. Kinney, T. D., Hegsted, D. M., and Finch, C. A., The influence of diet on iron absorption. I. The pathology of iron excess. J. Exper. Med., 1949, 90, 137.

50. Gillman, J., Mandelstam, J., and Gillman, T., A comparison of chemical and histological estimations of the iron and copper content of the livers of Africans in relation to the pathogenesis of cytosiderosis and cirrhosis (haemochromatosis). South African J. M. Sc., 1945, 10, 109.

51. Gillman, J., and Gillman, T., Structure of the liver in pellagra. Arch. Path., 1945, 40, 239.

52. Halkett, J. A. E., Peters, T., and Ross; J. F., Studies on the deposition and nature of egg yolk iron. In manuscript.

53. Elvehjem, C. A., Hart, E. B., and Sherman, W. C., The availability of iron from different sources for hemoglobin formation. J. Biol. Chem., 1933, 103, 61.

54. Granick, S., Iron metabolism and hemochromatosis. Bull. New York Acad. Med., 1949, 25, 403.

55. Granick, S., Ferritin. IX. Increase of the protein apoferritin in the gastrointestinal mucosa as a direct response to iron feeding. The function of ferritin in the regulation of iron absorption. J. Biol. Chem., 1946, 164, 737.

56. Granick, S., Ferritin: Its properties and significance for iron metabolism. Chem. Rev., 1946, 38, 379.

57. Granick, S., Iron metabolism. Bull. New York Acad. Med., 1954, 30, 81.

58. Wallerstein, R. O., and Robbins, S. L., Hemochromatosis after prolonged oral iron therapy in a patient with chronic hemolytic anemia. Am. J. Med. $1953,14,256$.

59. Case Records of the Massachusetts General Hospital. Weekly clinicopathological exercises. Case No. 38512. New England J. Med., 1952, 247, 992. 